\title{
Direct Surgery of Previously Coiled Large Internal Carotid Ophthalmic Aneurysm for the Purpose of Optic Nerve Decompression
}

\author{
Shuhei Kawabata ${ }^{1}$ Shingo Toyota ${ }^{1}$ Tetsuya Kumagai ${ }^{1}$ Tetsu Goto ${ }^{1}$ Kanji Mori ${ }^{1}$ Takuyu Taki ${ }^{1}$ \\ ${ }^{1}$ Department of Neurosurgery, Kansai Rosai Hospital, Hyogo, Japan \\ Address for correspondence Shingo Toyota, PhD, Department of \\ J Neurol Surg Rep 2017;78:e20-e25. \\ Neurosurgery, Kansai Rosai Hospital, 3-1-69 Inabaso, Amagasaki, \\ Hyogo 660-8511, Japan (e-mail: stshto@aol.com).
}

\begin{abstract}
Background Progressive visual loss after coil embolization of a large internal carotid ophthalmic aneurysm has been widely reported. It is generally accepted that the primary strategy for this complication should be conservative, including steroid therapy; however, it is not well known as to what approach to take when the conservative therapy is not effective.

Case Presentation We report a case of a 55-year-old female presenting with progressive visual loss after the coiling of a ruptured large internal carotid ophthalmic aneurysm. As the conservative therapy had not been effective, we performed neck clipping of the aneurysm with optic canal unroofing, anterior clinoidectomy, and partial

Keywords

- coiled aneurysm

- clipping

- mass effect

- nerve decompression removal of the embolized coils for the purpose of optic nerve decompression. After the surgery, the visual symptom was improved markedly.

Conclusions It is suggested that direct surgery for the purpose of optic nerve decompression may be one of the options when conservative therapy is not effective for progressive visual disturbance after coil embolization.
\end{abstract}

\section{Introduction}

For aneurysms in the ophthalmic segment of the internal carotid artery (ICA), the surgical treatment can be challenging and carry inherent risks such as visual disturbance. ${ }^{1}$ Recent reviews suggest the risk of new or worsened visual disturbance in 3 to $30 \%$ of surgically treated patients and 3 to $6 \%$ of endovascularly treated patients. ${ }^{2-6}$ Therefore, endovascular treatment is preferred as an initial treatment, especially in ruptured aneurysms. ${ }^{7}$

Concerning large ophthalmic segment aneurysms, progressive visual disturbance following coil embolization has been reported in some literatures..$^{2-6,8-16}$ It is thought that the increase of mass effect and perianeurysmal inflammation may cause progressive visual loss. ${ }^{8-16}$ The primary strategy for progressive visual disturbance should be conservative, including steroid therapy ${ }^{14}$; however, it is not well known as to what approach to take when the conservative therapy is not effective.

We experienced a case presenting progressive visual loss after the coiling of a ruptured large internal carotid ophthalmic aneurysm. As the conservative therapy had not been effective, we performed neck clipping of the aneurysm with optic canal unroofing, anterior clinoidectomy, and partial removal of the embolized coils for the purpose of optic nerve decompression and succeeded in marked visual symptom improvement. We present this unusual clinical course and discuss the importance of direct surgery when conservative therapy is not effective for progressive visual disturbance after coil embolization. To the best of our knowledge, this is the first case about visual symptom improvement by partial removal of the embolized coils and direct clipping. received

September 23, 2016

accepted after revision

December 21, 2016
DOI http://dx.doi.org/ $10.1055 / \mathrm{s}-0037-1598116$. ISSN 2193-6358. (c) 2017 Georg Thieme Verlag KG Stuttgart · New York
License terms

(c) $9 \oplus \$$ 


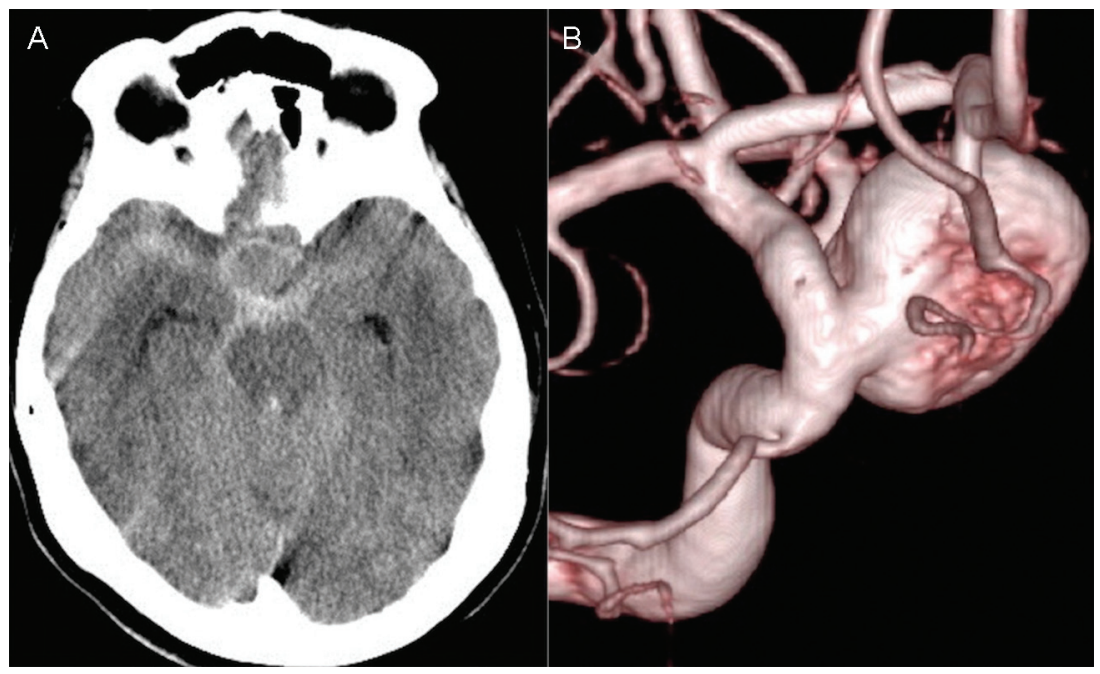

Fig. 1 (A) Initial computed tomography showed diffused subarachnoid hemorrhage. (B) Three-dimensional rotational angiography revealed a large saccular aneurysm. The dome and neck size of the aneurysm were 17 and $7 \mathrm{~mm}$, respectively.

\section{Case Report}

\section{Case Presentation}

A 55-year-old female presented with severe sudden onset headache. Initial computed tomography revealed diffused subarachnoid hemorrhage (WFNS [World Federation of Neurosurgical Societies] score: 1; Hunt and Hess score: 2) (-Fig. 1A). Digital subtraction angiography (DSA) detected a large aneurysm (diameter of $17 \mathrm{~mm}$, neck size of $7 \mathrm{~mm}$ ) in the ophthalmic segment of the right ICA (-Fig. 1B). In consideration of the location, size, and shape of the aneurysm, endovascular treatment was planned as the initial treatment. At the day of the onset, coil embolization had been performed using a double-catheter technique. The aneurysm was completely occluded with 22 bare platinum coils (-Fig. 2A, B).

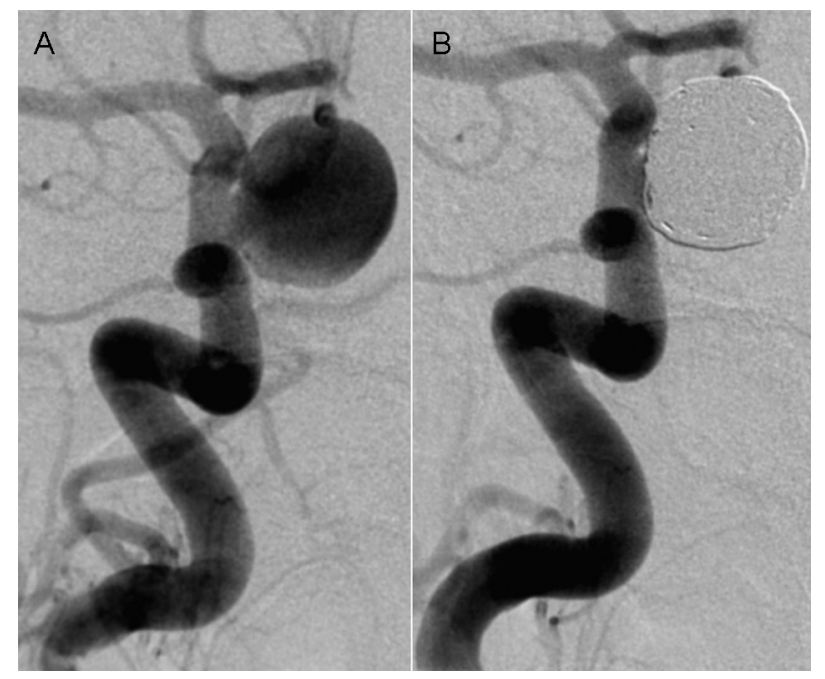

Fig. 2 (A) Anteroposterior angiographic views before coiling. (B) Anteroposterior angiographic views after coiling present near complete occlusion.
Six days after the coil embolization, the patient complained of slight visual disturbance. The postoperative course was uneventful with no symptomatic vasospasm, except for the visual disturbance. After discharge, she complained of progressive vision loss. Visual field test at 4 weeks after the coil embolization revealed a right central scotoma and a left superior temporal quadrantanopsia, and both visual acuity was decreased, especially in the right eye (right vision $[\mathrm{RV}]=30 \mathrm{~cm} /$ f.c., left vision $[\mathrm{LV}]=20 / 32$ ) (-Fig. 3). Coronal sections of magnetic resonance imaging (MRI) demonstrated that both optic nerves were compressed laterally, and the chiasm was elevated upward by the embolized aneurysm. Perianeurysmal brain edema of the T2-weighted images was not recognized apparently (-Fig. 4).

As a primary strategy, we decided to monitor her visual condition closely. At 11 weeks after the coil embolization, we confirmed complete obliteration of the aneurysm and patency of the ophthalmic artery by follow-up DSA (-Fig. 5). As the visual loss was worsened, we started steroid therapy at 11 weeks after the coil embolization. She was treated with intravenous betamethasone, $4 \mathrm{mg}$ per day for 2 days, followed by $10 \mathrm{mg}$ of prednisone per day, tapered during 3 weeks. Despite the steroid administration, the visual symptom was worsened progressively.

Four months after the coil embolization, direct surgery was planned for the purpose of decompression of the optic nerve. Balloon test occlusion before the operation demonstrated that the patient tolerated the occlusion of the right ICA for 20 minutes neurologically. The ratio of mean stump pressure to mean arterial pressure during balloon test occlusion was almost $60 \%$.

\section{Treatment}

We performed neck clipping of the aneurysm with optic canal unroofing, anterior clinoidectomy, and partial removal of the previously embolized coils (-Fig. 6). At first, the optic nerve and chiasm were strongly pressed by the aneurysm. By direct 

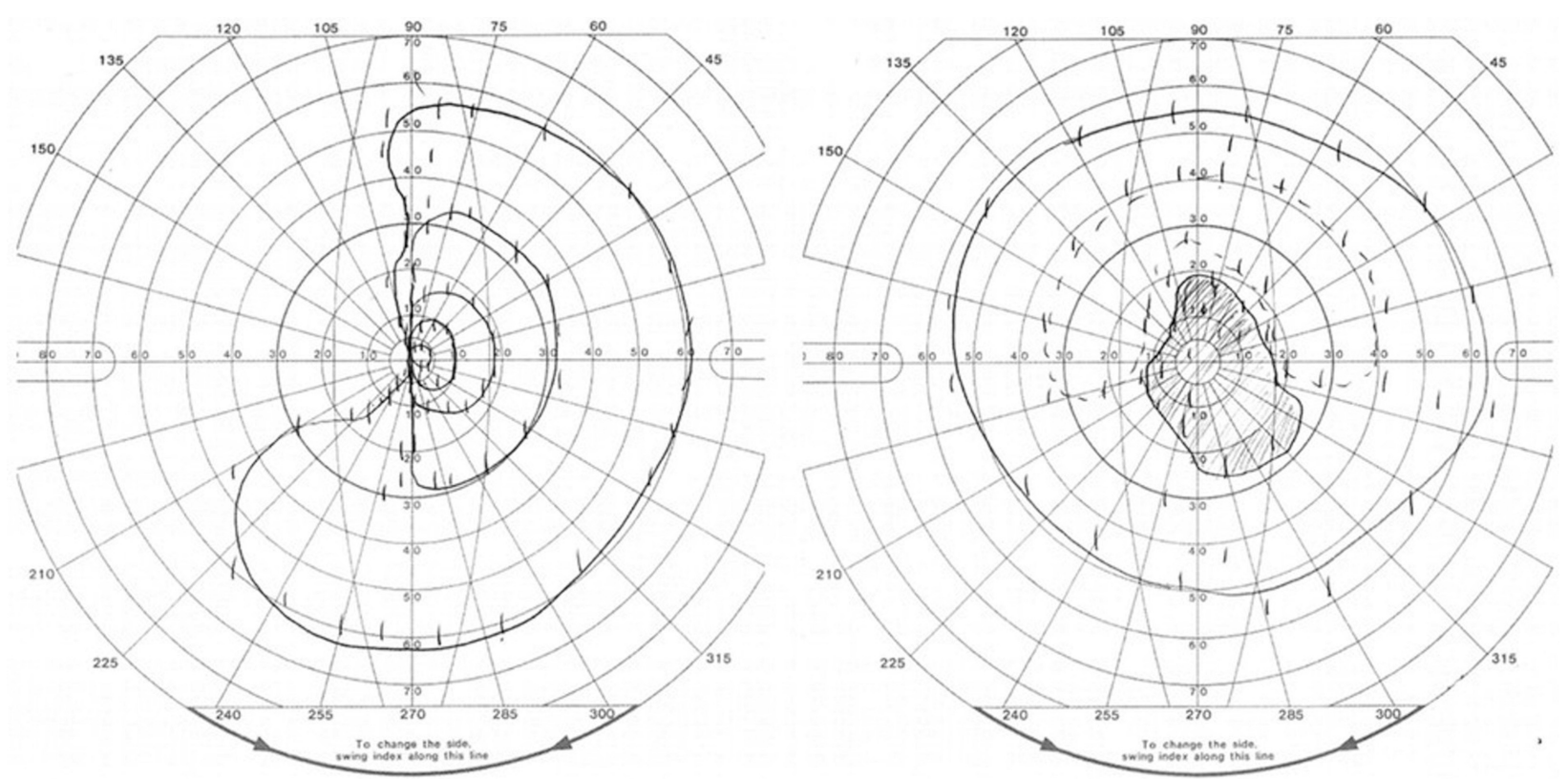

Fig. 3 Goldman visual field examination demonstrated a central scotoma in the right eye and left superior quadrantanopsia in the left eye, and in both, visual acuity was decreased.

surgery, the aneurysm was compacted and separated from the optic nerve.

\section{Postoperative Course}

The postoperative course was good without neurologic deterioration, and visual disturbance was improved subjectively at discharge. Visual field test at 1 month after the direct surgery demonstrated marked improvement $(\mathrm{RV}=20 / 200$;

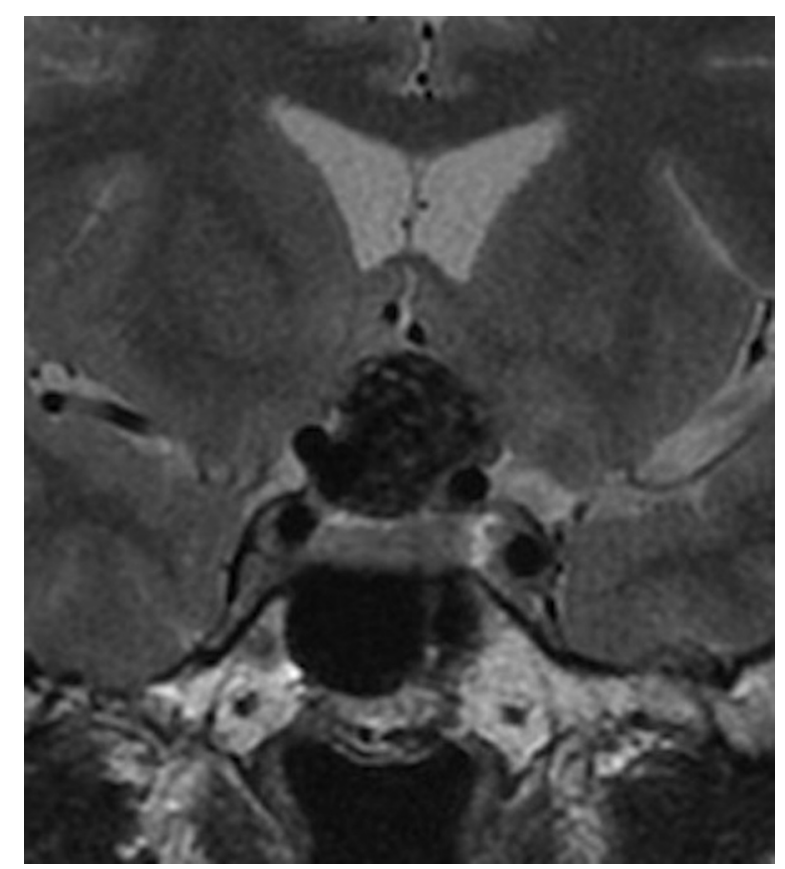

Fig. 4 Axial T2-weighted magnetic resonance imaging showing mass effect on the optic chiasma, and perianeurysmal brain edema was not found apparently.
$\mathrm{LV}=20 / 25)($ - Fig. 7). At 3 months after clipping, we confirmed complete obliteration of the aneurysm by follow-up DSA ( - Fig. 8).

\section{Discussion}

A large internal carotid ophthalmic aneurysm has a risk of visual disturbance caused by compression of the optic nerve.

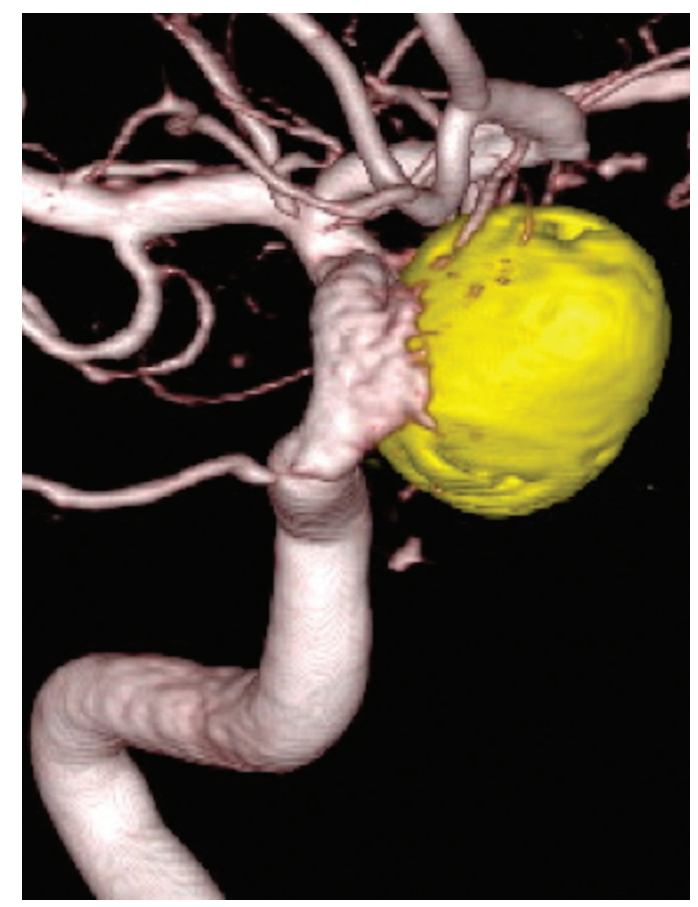

Fig. 5 Three-dimensional rotational angiography 11 weeks after coiling showed complete embolization of the aneurysm. 

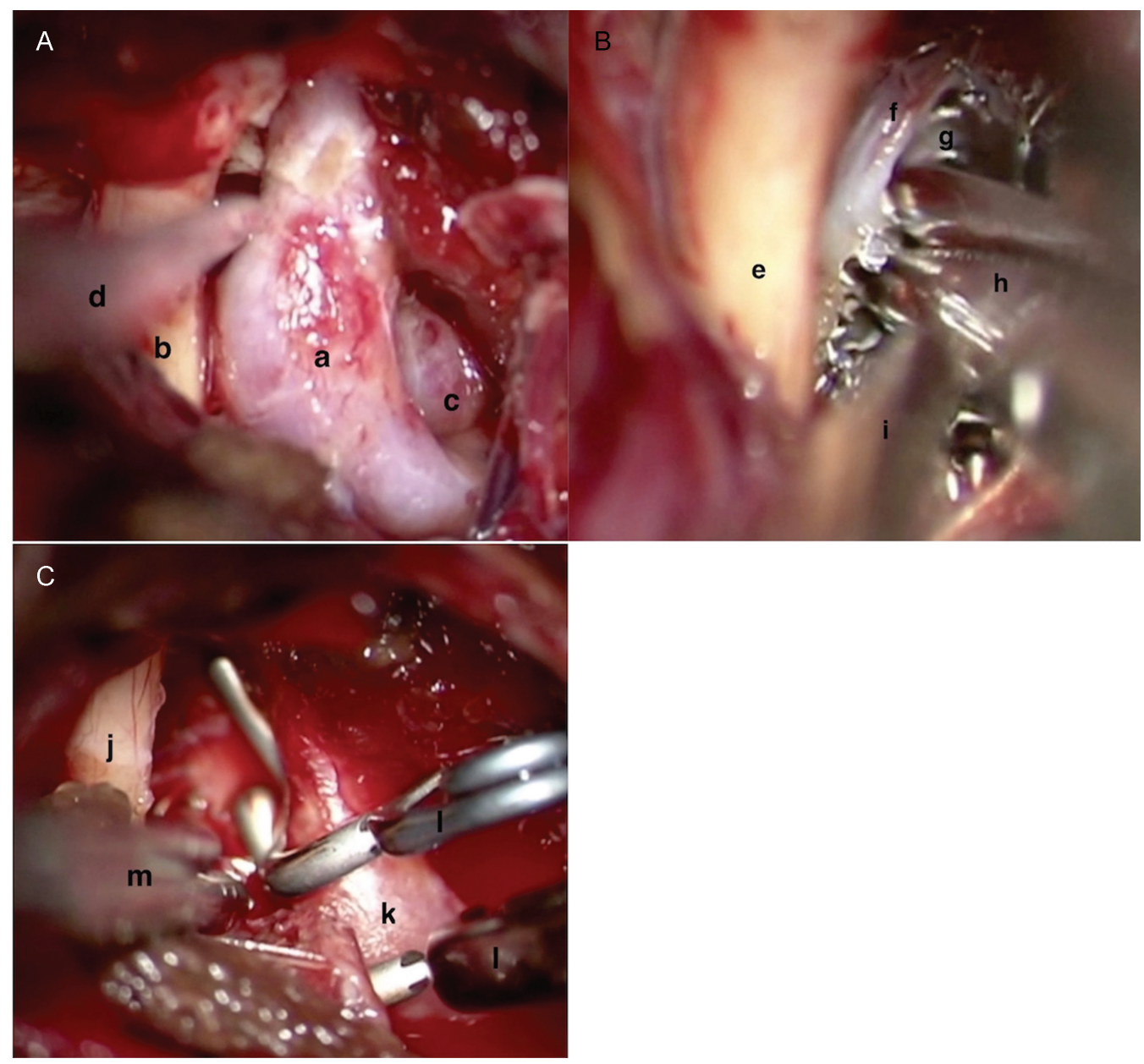

Fig. 6 The operative findings. (A) After optic canal was unroofed, anterior clinoid process was removed and the distal carotid dural ring was opened. a, Internal carotid artery (ICA); b, optic nerve; c, aneurysm; d, suction device. (B) Embolized coils were cut into small pieces and removed with a suction probe inside the aneurysmal dome. e, ICA; f, aneurysmal dome; $g$, coils; h, microscissors; i, suction device. (C) Neck clipping was performed using two fenestrated clips. j, Optic nerve; k, ICA; I, fenestrated clips; m, suction device.

Recent reviews suggest the risk of new or worsened visual disturbance in 3 to $30 \%$ of surgically treated patients and 3 to $6 \%$ of endovascularly patients. ${ }^{2-6}$ The goal of treatment of large internal carotid ophthalmic aneurysms is considered to be preservation of neurologic function as well as protection against bleeding.

There have been some reports of delayed onset progressive visual disturbance following coil embolization of internal carotid ophthalmic aneurysms. This complication may be observed without occlusion or ischemia of the ophthalmic artery and may be due to an increase of mass effect such as an aneurysm thrombosis, coil packing, aneurysm enlargement, pulsatile pressure, or perianeurysmal inflammation. ${ }^{1,8-16}$ In our case, MRI demonstrated that the optic nerve was pressed, perianeurysmal brain edema was not evident, and steroid therapy was ineffective. It was suggested that a mass effect such as coil packing and pulsatile pressure played an important part in this symptom.

It is generally accepted that the primary strategy for this complication should be conservative, including steroid therapy; however, there are few reports about what approach to take if the conservative therapy is not effective in delayed onset progressive visual disturbance following coil embolization of a large internal carotid ophthalmic aneurysm.

We thought that secondary strategy for this complication was to halt intra-aneurysmal flow and decrease mass effect. Two treatment options-parent artery occlusion or direct clipping-are available for decreasing mass effect. It was reported that parent artery occlusion was effective and 88\% of patients treated with carotid artery occlusion had visual improvement, ${ }^{9,15}$ but others reported that the complication associated with ICA occlusion included a $10 \%$ risk of transient ischemia, a $3 \%$ risk of permanent morbidity, and a $3 \%$ risk of mortality. ${ }^{17,18}$ In the present case, we thought that parent artery occlusion was not suitable. The insertion of coils into the ICA may create a new mass effect that worsened the symptom, even if the treatment halted pulsatile pressure of the ICA. Moreover, it was unclear whether the patient could tolerate ischemia by permanent occlusion of the ICA. On the other hand, direct clipping was suitable in this case because it could halt pulsatile pressure and decrease mass effect. To the best of our knowledge, there is no literature about visual improvement by direct clipping, but there is some literature about surgical clipping previously coiled aneurysms. Daou 

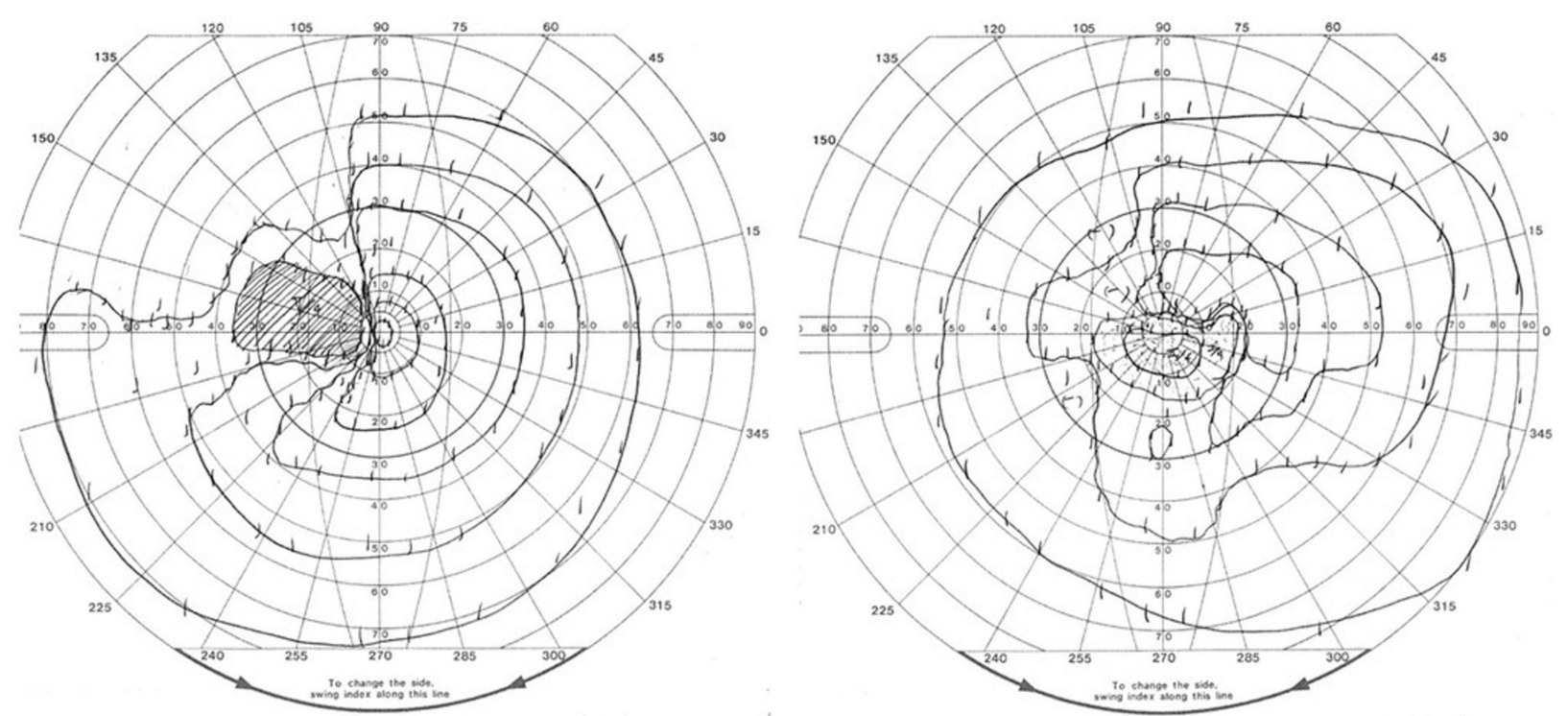

Fig. 7 Visual fields demonstrate marked improvement in both eyes 1 month after surgery.

et al reported that surgical clipping is safe and effective in treatment previously coiled aneurysms, ${ }^{19}$ and Shi et al reported that satisfactory outcomes can be achieved to perform surgical clipping. ${ }^{20}$

Additionally, by unroofing the optic canal, the optic nerve can be mobilized and relieved effectively, and by incision of the distal dural ring, the fixed portion of the ICA is released and the space between the ICA and the optic nerve can be increased. ${ }^{21,22}$ Considering the optic nerve decompression, endoscopic observation also can be useful as a less invasive technique. Although we did not use endoscopic technique in

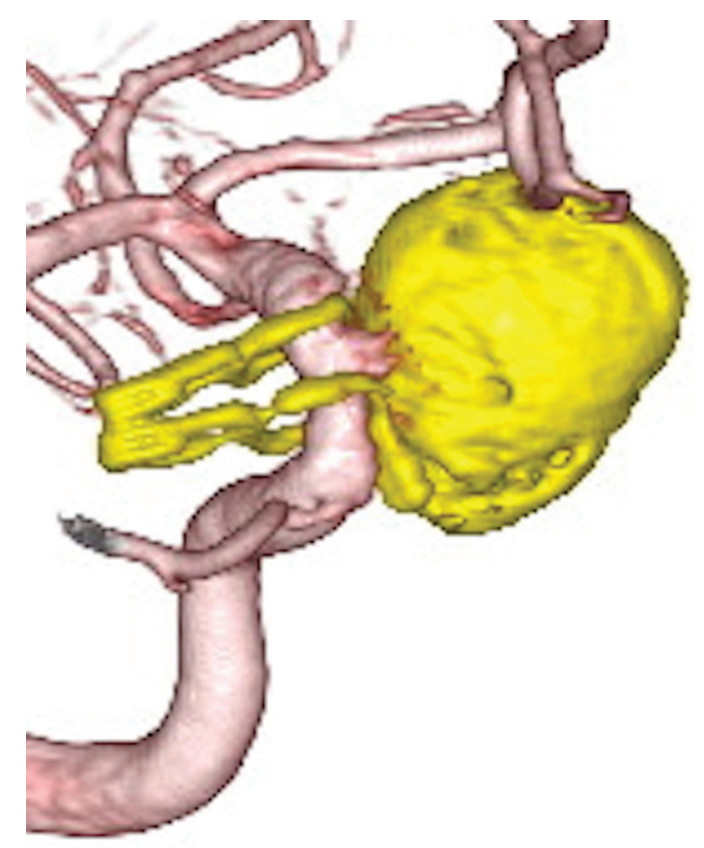

Fig. 8 Three-dimensional rotational angiography 3 months after surgery showed compete obliteration of the aneurysm. this case, it may be feasible because anterior clinoidectomy and the optic nerve decompression can be performed safely using endoscopic assistance. ${ }^{23}$

By direct surgery, the aneurysm was compacted and separated from the optic nerve and visual disturbance was improved. This case demonstrates that optic nerve decompression by direct surgery with removal coil can be one of the options, and visual symptom improvement can be achieved by selecting appropriate case. This is the first case about visual symptom improvement by partial removal of the embolized coils and direct clipping.

\section{Conclusion}

It is suggested that direct surgery for the purpose of optic nerve decompression may be one of the options when conservative therapy is not effective for progressive visual disturbance after coil embolization.

\section{References}

1 Kattner KA, Bailes J, Fukushima T. Direct surgical management of large bulbous and giant aneurysms involving the paraclinoid segment of the internal carotid artery: report of 29 cases. Surg Neurol 1998;49(05):471-480

2 Beretta F, Andaluz N, Zuccarello M. Aneurysms of the ophthalmic (C6) segment of the internal carotid artery: treatment options and strategies based on a clinical series. J Neurosurg Sci 2004;48(04): 149-156

3 Hoh BL, Carter BS, Budzik RF, Putman CM, Ogilvy CS. Results after surgical and endovascular treatment of paraclinoid aneurysms by a combined neurovascular team. Neurosurgery 2001;48(01): 78-89, discussion 89-90

4 Iihara K, Murao K, Sakai N, et al. Unruptured paraclinoid aneurysms: a management strategy. J Neurosurg 2003;99(02):241-247

5 Kanagalingam S, Gailloud P, Tamargo RJ, Subramanian PS, Miller NR. Visual sequelae after consensus-based treatment of ophthalmic artery segment aneurysms: the Johns Hopkins experience. J Neuroophthalmol 2012;32(01):27-32 
6 Yadla S, Campbell PG, Grobelny B, et al. Open and endovascular treatment of unruptured carotid-ophthalmic aneurysms: clinical and radiographic outcomes. Neurosurgery 2011;68(05): 1434-1443, discussion 1443

7 Molyneux AJ, Kerr RS, Yu LM, et al; International Subarachnoid Aneurysm Trial (ISAT) Collaborative Group. International subarachnoid aneurysm trial (ISAT) of neurosurgical clipping versus endovascular coiling in 2143 patients with ruptured intracranial aneurysms: a randomised comparison of effects on survival, dependency, seizures, rebleeding, subgroups, and aneurysm occlusion. Lancet 2005;366(9488):809-817

8 Durst CR, Starke RM, Gaughen J, et al. Vision outcomes and major complications after endovascular coil embolization of ophthalmic segment aneurysms. AJNR Am J Neuroradiol 2014;35(11): 2140-2145

9 Heran NS, Song JK, Kupersmith MJ, et al. Large ophthalmic segment aneurysms with anterior optic pathway compression: assessment of anatomical and visual outcomes after endosaccular coil therapy. J Neurosurg 2007;106(06):968-975

10 Loumiotis I, D'Urso PI, Tawk R, et al. Endovascular treatment of ruptured paraclinoid aneurysms: results, complications, and follow-up. AJNR Am J Neuroradiol 2012;33(04):632-637

11 Meling TR, Sorteberg W, Bakke SJ, Jacobsen EA, Lane P, Vajkoczy P. Case report: a troublesome ophthalmic artery aneurysm. J Neurol Surg Rep 2014;75(02):e230-e235

12 Schmidt GW, Oster SF, Golnik KC, et al. Isolated progressive visual loss after coiling of paraclinoid aneurysms. AJNR Am J Neuroradiol 2007;28(10):1882-1889

13 Schuss P, Güresir E, Berkefeld J, Seifert V, Vatter H. Influence of surgical or endovascular treatment on visual symptoms caused by intracranial aneurysms: single-center series and systematic review. J Neurosurg 2011;115(04):694-699

14 Stracke CP, Krings T, Möller-Hartmann W, Mahdavi A, Klug N. Severe inflammatory reaction of the optic system after endovas- cular treatment of a supraophthalmic aneurysm with bioactive coils. AJNR Am J Neuroradiol 2007;28(07):1401-1402

15 Tawk RG, Villalobos HJ, Levy EI, Hopkins LN. Surgical decompression and coil removal for the recovery of vision after coiling and proximal occlusion of a clinoidal segment aneurysm: technical case report. Neurosurgery 2006;58(06):E1217, discussion E1217

16 Turner RD, Byrne JV, Kelly ME, et al. Delayed visual deficits and monocular blindness after endovascular treatment of large and giant paraophthalmic aneurysms. Neurosurgery 2008;63(03): 469-474, discussion 474-475

17 Szikora I, Marosfoi M, Salomváry B, Berentei Z, Gubucz I. Resolution of mass effect and compression symptoms following endoluminal flow diversion for the treatment of intracranial aneurysms. AJNR Am J Neuroradiol 2013;34(05):935-939

18 Fox AJ, Viñuela F, Pelz DM, et al. Use of detachable balloons for proximal artery occlusion in the treatment of unclippable cerebral aneurysms. J Neurosurg 1987;66(01):40-46

19 Daou B, Chalouhi N, Starke RM, et al. Clipping of previously coiled cerebral aneurysms: efficacy, safety, and predictors in a cohort of 111 patients. J Neurosurg 2016;125(06):1337-1343

20 Shi L, Yuan Y, Guo Y, Yu J. Intracranial post-embolization residual or recurrent aneurysms: Current management using surgical clipping. Interv Neuroradiol 2016;22(04):413-419

21 Guyer DR, Miller NR, Long DM, Allen GS. Visual function following optic canal decompression via craniotomy. J Neurosurg 1985; 62(05):631-638

22 Matsuyama T, Shimomura T, Okumura Y, Sakaki T. Mobilization of the internal carotid artery for basilar artery aneurysm surgery. Technical note. J Neurosurg 1997;86(02):294-296

23 Yang Y, Wang H, Shao Y, Wei Z, Zhu S, Wang L. Extradural anterior clinoidectomy as an alternative approach for optic nerve decompression: anatomic study and clinical experience. Neurosurgery 2006;59(02):253-262 